\title{
Energy in the 21st Century: New Challenges and Goals
}

\author{
L. Bennett and T. Müller \\ J.W. Byam \\ A. Miremadi \\ Y. Sinyak
}

CP-93-3

February 1993

Presented at the 15th Congress of the World Energy Council, Energy and Life, Madrid, September 20-25, 1992.

Collaborative Papers report work which has not been performed solely at the International Institute for Applied Systems Analysis and which has received only limited review. Views or opinions expressed herein do not necessarily represent those of the Institute, its National Member Organizations, or other organizations supporting the work. 


\section{Foreword}

The Vienna Four, consisting of the four Vienna-based international organizations (IAEA, IIASA, OPEC, and UNIDO), was formed in February 1990 to increase energy market transparency and enhance better energy planning through the exchange of information, assessing gaps in existing programs and supporting joint studies.

Regular activities of the Vienna Four include research and inter-agency networking at the level of a Task Force, composed of elected middle managers of the four organizations. The Task Force reports its activities to the Chief Executives of the Four. Current activities of the Vienna Four include several large and small projects that are supported by the existing resources.

The following joint paper was presented at the 15th Congress of the World Energy Council in Madrid last year. This is the first of what is hoped will be a series of publications. 



\section{Preface}

In the next century energy will remain the pillar of social development and wealth. The demand for energy will continue to increase apace with economic growth in the medium term and population growth in the longer term. In several countries, development planning strategies might also conflict sharply with environmental concerns, thus complicating the implementation of timely environmental protection policy strategies. However, early introduction and deployment of safe and clean technologies could reduce future economic burdens such as compensation payments for health and the environmental costs of energy use.

The major goal in developing long-term energy projections is to identify those principal trends and tendencies that will prevail over the time period under consideration rather than to define exactly the various factors constituting the scenario or system being studied. Whereas long-term projections can concentrate on many different aspects, the major focus is on the possible exhaustion of cheap energy resources and the environmental and climatic impact of energy systems. Scenarios and options for global and regional energy systems are addressed in this paper with the aim of identifying a smooth transition from the present structure based primarily on fossil fuels to a future structure based on the more efficient and balanced use of fossil fuels, nuclear energy and renewable energy.

It is clear that energy resources are available in sufficient quantity in the medium term to support national development and individual well-being. The energy mix adopted by each country will depend on the economical and ecological use of the indigenous resource base and global/regional constraints on greenhouse gas emissions. Trade-offs between environmental impact and economic development must be explored and incorporated into national energy policies.

The challenge of the next decades will place greater emphasis on energy sources and power generation technologies that have the potential to minimize damage to health and the environment, while at the same time being economically viable and deployable on a broad scale so as to meet global energy demands. Energy availability, security of supply, and the pricing structure of primary as well as final energy sources are important issues on the decision-makers' agendas. Improvements in technology transfer, financial mechanisms, and new more effective institutional frameworks are required, if a global environmentally compatible energy strategy is to be achieved for the next century. 



\title{
Energy in the 21st Century: New Challenges and Goals
}

\author{
L. Bennett and T. Müller* \\ J.W. Byam ** \\ A. Miremadi *** \\ Y. Sinyak ${ }^{* * * *}$
}

\section{Introduction}

\section{$1.1 \quad$ Background}

In the next century energy will remain the pillar of social development and wealth. The demand for energy will continue to increase apace with economic growth in the medium term and population growth in the longer term. Different views on the objectives of economic growth in developing countries, (where the emphasis will be on social development) as compared to developed countries (where sustainability of achievements will be the major goal), lend varying momentum to energy growth in each region. In several countries, development planning strategies might also conflict sharply with environmental concerns, thus complicating implementation of timely environmental protection policy strategies. On the other hand, early introduction and deployment of safe and clean technologies could reduce future economic burdens such as compensation payments for health and the environmental costs of energy use.

The substantial oil price increases of 1973/1974 and 1979/1980 had a major impact on fuel substitution, energy conservation and energy policy. As a result, the industrialized countries became sensitive to developments in oil pricing and energy security. They set about expanding their strategic reserves and invested billions of dollars in opening up new reserves, developing alternative energies and improving end-use efficiency and conservation. However, with the lack of further growth in oil/gas prices leveling off, interest has waned and future energy markets face uncertainties arising from energy policies in general and environmental requirements in particular. These uncertainties call for a rethinking of global/regional energy policies and the development of a unified approach.

In the current energy debate, major priorities can be grouped under three main headings: energy security, environmental policies, and economic factors.

\footnotetext{
*International Atomic Energy Agency

** United Nations Industrial Development Organization

*** Organization of the Petroleum Exporting Countries

****International Institute for Applied Systems Analysis
} 


\subsubsection{Energy security}

The concept of energy security has a number of inter-related dimensions. On the one hand, consumers require security of supply, in terms of both volume and price, so that they can enhance their economic growth and competitiveness. On the other hand, the producers, be they States or private enterprises, need security of demand, in terms of both volume and price, so that they can provide capital for the maintenance and/or expansion of production levels. Furthermore, the energy exporting developing countries need that security so that they can plan economic development for as long as they have energy reserves. Uncertainties in energy demand affect producers and consumers alike. Most forecasts indicate increasing demand for energy in the foreseeable future which will require considerable investment in maintaining current energy production levels, developing new production and introducing new technologies. However, a number of opportunities offer themselves which, if implemented, would most certainly lower both demand and price. Given future uncertainties, substantial investments will not be undertaken. However, unless expansion is realized, the world energy balance, the basis of most energy studies, would change, one very likely outcome being a marked shortfall in supply and a sharp increase in prices.

\subsubsection{Environmental policies}

For several decades, the environmental and health impact of energy, in particular energy production and use, has been a cause of growing concern to individuals and groups monitoring the quality of the environment. The major energy-related health and environment concerns are: air, land and sea pollution (smog, acid rain, oil spills, etc.); radioactive radiation; ozone layer depletion; and climate change. The impact of energy on ozone layer depletion is thought to be rather slight, whereas the impact of energy use and energy conversion on global warming has been the subject of many studies and debates, most of which have concentrated on the impact of fossil fuels. The impact on energy development of action taken to prevent further damage to the environment will very much depend on the nature of the policies adopted. While international unanimity prevails on the need to protect the environment, views vary widely on the approaches and their effectiveness. The many options can be classified into three types: economic, technological and social. The economic options take on the form of fiscal measures, such as regulations, taxation and tradable permits. Technological options, whether drawn from methods already available or still to be developed in the industrialized world, would increase the efficiency of energy consumption in addition to greatly reducing or treating emissions prior to discharge into the atmosphere. Social solutions build on increased awareness of the need to protect the environment by means of conservation, changes in lifestyle and the more efficient use of "clean" energy.

\subsubsection{Economic factors}

Steady global economic growth through continuous development in various sectors is a key factor in improving economic well-being of people throughout the 
world. Energy is, of course, the driving force behind economic growth; if energy costs are excessive, they could have a negative impact on the economy. As indicated in this paper, fossil fuel resources are plentiful and cost effective energy systems are a decisive element if economic growth and development are to continue.

Energy demand forecasts and the role of the respective supply options thus take on major significance in policy development. Prime consideration can be given to the use of energy, its impact on the environment and the security of energy supply, as well as the potential for energy conservation and improved efficiencies. The principal factors governing energy utilization have to be evaluated in their economic context.

\subsection{Basic Findings}

The major goal in developing long-term energy projections is to identify those principal trends and tendencies that will prevail over the time period under consideration rather than to define exactly the various factors constituting the scenario or system being studied. Whereas long-term projections can concentrate on many different aspects, the major focus is on the possible exhaustion of cheap energy resources and the environmental and climatic impact of energy systems.

From a long-term perspective, the problem of climatic change could become the central issue. Energy systems will continue to contribute to atmospheric greenhouse gases, including $\mathrm{CO}_{2}$ accumulations. In order to reduce or smooth over unexpected climatic changes with uncertain amplitudes and unpredictable consequences, new approaches to solving energy problems are needed: all the more so in the light of the recent Intergovernmental Panel on Climate Change (IPCC) statement that "to stop greenhouse gas concentration growth, we need to cut down their emissions substantially." Achievement of this objective calls for efforts on the part of both developed and developing countries. Much remains to be done to reduce the uncertainties related to the role of sinks and sources in global warming, measures will have to be taken to adapt to the new future environment. Different scenarios and options for global and regional energy systems will have to be considered with the aim of identifying a smooth transition from the present structure based primarily on fossil fuels to a future structure based on the more efficient and balanced use of fossil fuels, nuclear energy and renewable energy.

It is clear that energy resources are available in sufficient quantities in the medium-term to support national development and individual well-being. The energy mix adopted by each country will depend on the extent to which the indigenous resource base can be used in a manner that is economically and ecologically compatible. Any technology that converts energy into electricity or steam and power will affect the environment in some way and at different stages of the fuel cycle. Hence no technology offers a specific deployment bonus from the outset. However, on the basis of present knowledge and extraction economics, the long-term energy resource situation looks less bright for liquid and gaseous fuels. Solid fuels are abundantly available, as are fuels for nuclear power plants (assuming reprocessing of spent material). 


\section{Future energy resources and scenarios}

\section{$2.1 \quad$ Future energy resources}

Energy is the driving force of the global economy and an essential element of human existence. Energy, particularly energy derived from fossil fuels, will continue to play a prominent role, since fuel reserves are abundant and could last for many decades to come. However, the ultimate availability of these energy resources and the size of recoverable fossil energy reserves (i.e. resources that are recoverable at competitive prices) change with price levels, recovery technology developments, geopolitical conditions and other factors. The amount of uranium resources available for use in once-through electricity generation cycles are sufficient to sustain nuclear programmes for about 200 years: depending on the cost of exploitation, large resources could be tapped. At current production levels, the nonrenewable conventional energy resource base (i.e identified plus undiscovered reserves) could last for more than 70 years for crude oil to more than 100 and 600 years for natural gas and coal, respectively ( See Table 1 below).

Table 1

World non-renewable conventional energy resource base (January 1990) $\left(10^{9}\right.$ toe) (estimated)

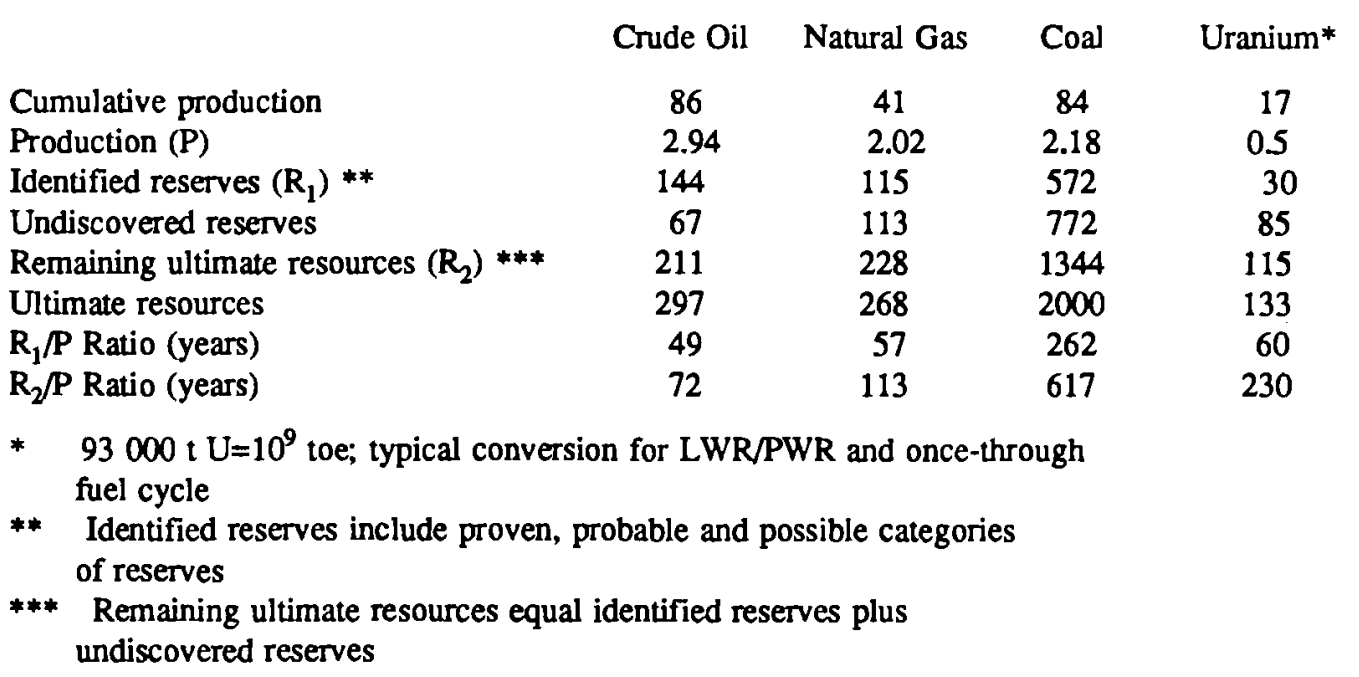

Sources: $[1,2,3,4]$

From Table 1, it can be seen that cumulative production of resources has not reached an appreciable level of the original inventory of fuels. Even if it is assumed that the resource base could not be increased, the current levels of production could be sustained well beyond the time requirements to develop alternate energy technologies.

Of the renewable sources of energy, hydroelectric power is at present the main contributor to electricity production. Despite its large theoretical potential, environmental concerns and economic constraints will limit growth of future usage. Global resources of geothermal energy are rather limited, but could play a significant 
role in specific regional and local areas. The contributions of other renewable energy sources, in particular wind and solar power, are expanding. The theoretical resource base of both energy sources is immense and outstrips the world's total energy requirements. However, at present only a small fraction of this dispersed energy is actually captured and used to generate electricity. The future contribution of solar and wind energy will depend largely on the success of R\&D efforts to increase the efficiency of those technologies and reduction of the associated costs.

\subsection{The world energy outlook}

World demand for both energy services and supplies will continue to increase, for some time yet, at least into the early part of the next century. The increase will be mainly governed by economic growth in the medium term and by population growth in the longer term. Energy consumption will increase more in developing countries than in industrialized countries. In the next half-century however, the rates of increase in energy consumption will be lower than in the past. In fact, in higher income countries total energy consumption may even decrease, particularly as a result of steps taken to address environmental concerns about global warming. Elsewhere, scenarios calling for significant growth in energy supplies point to stresses on energy resource and financial resource availability. As a result, such scenarios may simply not be practicable.

A fundamental problem is that any global effort to project appropriate future energy scenarios is beset by uncertainties: these include demographic, economic, social and political complications, as well as technological uncertainties. A compounding factor is an incredible diversity of national and sectoral conditions. It is difficult to arrive at firm decisions on meeting long term energy and environmental needs when long-term economic, political and energy conditions cannot be forecast with any degree of confidence. However, visions of future developments are essential to energy and electricity planning and are major factors in any decision making process.

Population growth will remain a major factor in energy demand, in particular in developing countries. It will in all probability be matched by an increasing demand for satisfaction of basic needs. The world population has doubled over the past 40 years, and it is expected to double again by the middle of the next century. By the year 2050, the developing country population will probably number more than 9 billion as against less than 4 billion in 1988. This development in itself will bring inordinate pressure to bear on future energy demand and supply patterns, not to speak of the additional demand for improvements in basic conditions prevailing in developing countries.

\subsection{Two scenarios}

As a basis for discussion, two future energy outlooks are considered. Both scenarios assume similar levels of global economic growth, 2-3\% per year, growth being higher in developing countries than in industrialized countries. They also assume improvements in energy efficiencies yielded by measures taken to reduce environmental impacts. 
To illustrate the issues which merit policy reflection, the scenarios were chosen for two time horizons: the medium term covering the period up to 2010, and the longer term extending to 2050 . Two energy supply options are considered for each scenario:

(a) a dynamic-as-usual scenario; and

(b) a controlled $\mathrm{CO}_{2}$ emission scenario.

The dynamic-as-usual scenario assumes that past and present trends will continue with no major environmental restrictions reducing or reversing world energy demand. For the period 1990-2010, the controlled $\mathrm{CO}_{2}$ emission scenario assumes that by 2010, only the OECD region will have stabilized $\mathrm{CO}_{2}$ emissions at 1990 levels, some developing countries will continue to consume energy at the rate assumed in the dynamic-as-usual scenario. In practice, if the concerns about climate change prove to be correct, remedial measures will have to include all greenhouse gas sources, including methane, and parallel efforts will have to be undertaken to enhance greenhouse gas sinks and reservoirs.

The controlled $\mathrm{CO}_{2}$ emission scenario for the longer term reflects the views of IPCC and assumes that a $\mathrm{CO}_{2}$ sustainable level will be reached sometimes beyond 2050 when $\mathrm{CO}_{2}$ releases are practically balanced with the absorbing capacity of nature. This option implies no future increases in atmospheric $\mathrm{CO}_{2}$ concentrations resulting in no further increases in the global temperature (IPCC expects that stabilization of the global $\mathrm{CO}_{2}$ concentration could be achieved by significantly reducing greenhouse gas emissions, including a $60 \%$ reduction of carbon dioxide emissions compared to current levels). Strong reservations exist, however, on the realistic need to cut $\mathrm{CO}_{2}$ emission levels drastically and hence the use of fossil fuels.

Some key messages emerge from the energy supply/demand scenarios:

- Energy demand will continue to grow,

- All energy forms will be required to balance the energy demand,

- Energy supply will continue to rely heavily on fossil fuels, with increasing shares of natural gas and coal, and declining shares of oil,

- Hydro, nuclear and other energies will increase their share in the energy market but will not surpass the share of fossil fuels.

The four organizations' collective view on the future world primary energy supply and demand situation and $\mathrm{CO}_{2}$ emissions are presented in Table 2 below. Given the extreme concern over global environmental change, the main issue is carbon emissions which are also cited in Table 2. 
Table 2

\begin{tabular}{|c|c|c|c|c|}
\hline Year & 1990 & 2000 & 2010 & 2050 \\
\hline Energy demand & 8045 & $\begin{array}{c}\left(10^{6} \text { toe }\right) \\
8570-9300\end{array}$ & $9800-11160$ & $18100-21000$ \\
\hline Energy supply & 3185 & $3400-3500$ & $3800-3900$ & $5400-5800$ \\
\hline Oil & 2258 & $2200-2600$ & $2700-3200$ & $4000-5000$ \\
\hline Coal & 1596 & $1870-2000$ & $2000-2500$ & $5000-6100$ \\
\hline Gas & & & & \\
\hline $\begin{array}{l}\text { Hydro, nuclear \& } \\
\text { others }\end{array}$ & 1006 & $1100-1200$ & $1300-1560$ & $3700-4100$ \\
\hline Fuel shares & & (percentage) & & \\
\hline Oil & 40 & $40-38$ & $39-35$ & $30-28$ \\
\hline Coal & 28 & $25-28$ & $28-29$ & $22-24$ \\
\hline Gas & 20 & $22-21$ & $21-22$ & $28-29$ \\
\hline \multirow[t]{2}{*}{$\begin{array}{l}\text { Hydro, nuclear \& } \\
\text { others }\end{array}$} & 12 & 13 & $13-14$ & 20 \\
\hline & & ( $10^{9}$ tonnes & of carbon) & \\
\hline $\mathrm{CO}_{2}$ emissions & 6.5 & $7.1-7.7$ & $8.0-11.0$ & $13.0-15.0$ \\
\hline
\end{tabular}

\subsubsection{Medium-term projections}

The basic assumptions in both medium-term projections are related to the development of oil prices, gross domestic products (GDP) and energy intensity. It is assumed that oil prices will remain constant in real terms at US \$21/bbl (1991) and will only increase with inflation, average world GDP growth will be $2.9 \%$, and world energy demand will grow by $1.8 \%$ and $1.6 \%$ for the periods $1990-2000$ and 2000-2010, respectively. Energy intensity (boe/ US \$1000 GDP) in OECD countries will be reduced from 2.99 in 1990 to 2.22 in 2010, while the energy intensity for the world as a whole (excluding the former centrally planned economies) is projected to decline from 3.22 in 1990 to 2.55 in 2010.

Whereas the rate of economic growth is expected to level off in OECD countries over the next two decades, the developing countries are expected to experience appreciable economic growth. This will require increasing supplies of energy in both the short and long term. The rate of growth will vary depending on the economic base and the levels of industrialization in individual countries. In general, the greatest need in developing countries is to satisfy basic requirements as compared to energy development and environmental protection, both of which will also require international co-operation for resolution.

In the light of the global and regional diversities in economic, demographic and other parameters, total world demand for primary energy in the medium-term is expected to rise from $8.0 \times 10^{9}$ toe in 1990 to $8.6-9.3 \times 10^{9}$ toe in 2000 and 9.8 $11.2 \times 10^{9}$ toe in 2010 . The demand for oil is forecast to increase from $3.2 \times 10^{9}$ toe in 
1990 to $3.8-3.9 \times 10^{9}$ toe in 2010 . The demand for other sources of energy is also expected to rise over the same period. Thus, the share of oil in the primary energy demand may fall from $40 \%$ in 1990 to $35-39 \%$ in 2010 . The share of other fossil fuels is predicted to change as follows: coal from $28 \%$ in 1990 to $28-29 \%$ in 2010 and natural gas from $20 \%$ in 1990 to $21-22 \%$ in 2010 . The proportion of primary electricity (mainly hydro and nuclear) is also expected to grow from $12 \%$ in 1990 to $13-14 \%$ in 2010.

For many reasons, the problems of oil supply remain central to the energyrelated issues over the medium term. Since non-OPEC oil supply has already stabilized at current prices and is expected to fall in the future, additional future oil supplies must come from OPEC member countries. This conclusion is borne out by close examination of the respective reserves and reserves-to-production ratio of both oil supply regions. Current OPEC proven crude oil reserves stand at more than $75 \%$ of total world proven oil reserves. Their lifespan could extend to more than 90 years as compared to other reserves with a lifespan of about 17 years. The situation, therefore, could become serious, especially when the falling former Soviet oil exports are taken into consideration. Under these circumstances, even a limited disruption in supply could cause a major oil price shock. In order to overcome this challenge, OPEC member countries have already launched ambitious programmes to expand their annual production capacities to a total of 1700 and $1900 \mathrm{mt}$ (or 34 and 38 million boe/d) in 1995 and 2000, respectively.

\subsubsection{Long-term projections}

Given current policies, energy developments over the next two decades will have an impact on energy needs and environmental factors into the future. It is therefore important that full consideration be given to developments beyond 2010 . Furthermore, it can be expected that the estimates of global final energy demand over the next 60 years will be substantially lower than the projections drawn up in the early 1980s, when energy-saving policy issues were underestimated and the existence of large inertia in energy systems had been assumed.

If they are to meet their populations' basic needs, the developing countries will of necessity consume more energy and hence contribute significantly to the growth in the global demand for energy in the next century. Per capita consumption in developing countries is expected to increase from 0.25 toe today to $0.45-0.9$ toe in 2050. These levels will still be much lower than in developed countries and will not have reached near-saturation levels. The assumptions of increased per capita energy use in developing countries, combined with their growth in population, point to developing countries taking on an increasingly dominant role in world energy demand. Their share of total commercial energy demand will increase from one quarter in 1988 to between two-thirds and three-quarters by the year 2050. On the other hand, per capita energy demand in developed countries after peaking at the beginning of the next century at the level of $3.4-3.7$ toe will slowly decline to 2 2.6 toe by the middle of the century.

Responding to needs both in developing and developed countries, fossil fuels will continue to be the main energy supply source for a considerable time to come. 
The world will not 'run out' of oil, but supplies will begin to decline slowly by the middle third of the next Century. Natural gas consumption will rise for several decades into the century, with additional transport options contributing to flexibility and restraints on energy prices. Coal will continue to compete on an equal footing with other sources of energy in many countries. From the standpoint of electricity generation in particular, coal is abundant and relatively inexpensive; it can be "cleaned" and is a familiar option that will not be easily displaced.

The relative contributions of the remaining commercial energy supply options are less certain. Energy sources such as nuclear and hydropower have the potential to play very substantial roles in responding to global demand; renewable sources other than hydropower will also be able to play a more pronounced role as technologies improve. The shares assumed by the various options, however, will depend on future energy requirements, production costs, technological changes and social preferences.

A dynamic-as-usual future induces energy stresses that would be particularly severe for those developing countries without indigenous energy resources. Constant per capita energy use in industrialized countries, coupled with their continuing economic growth, implies an ability to pay higher prices for convenient sources of energy: notably, oil and gas. Some developing countries will find their economic growth limited by their inability to pay for energy imports and by the difficulties they encounter in implementing innovative technologies and sources of energy, unless the industrialized countries adopt a substantial programme for the development of nuclear power or other "clean" technologies. Securing investment capital for electricity production will remain a particular problem. An alternative result could be a transition from the targeted growth future towards the targeted higher efficiency future, where fuel price shocks reinforce the environmental merits of using energy and electricity efficiently.

Energy consumption in developed countries will practically remain at current levels or even slightly decrease (in some countries, energy consumption is expected to decline in the near future). Global energy consumption growth will take place primarily in the developing countries where an increase of $2-5$ times is expected up until 2050. This will result in an increase of developing countries' share in total global consumption from about one quarter in 1990 to about two-thirds by the middle of the next century. If the worries about the atmospheric impact of increasing $\mathrm{CO}_{2}$ concentrations persist long enough (i.e a decade), the burden of global energy problems will appear to shift from developed to developing countries and could create new "hot" issues in international relations, unless corrective measures are taken.

Changes in the primary energy mix during the next $60-70$ years will depend on the energy strategies applied. For example, in the "normal" course of development (i.e. without special constraints on the use of fossil fuels or nuclear energy) coal production will increase by about $3 \times 10^{9}$ toe, crude oil production will grow by $2.6 \times 10^{9}$ toe, and natural gas production will increase almost 3 times reaching $4.5 \times 10^{9}$ toe. The total share of non-carbon "fuels" (nuclear and renewable energies) will reach about $20 \%$. However, if major abatement measures (for the global climate) 
are implemented, the share of fossil fuels will have to be reduced by 2050 (the lower range of Table 2 or even lower). A decline in the use of coal and crude oil, which have much higher $\mathrm{CO}_{2}$ emissions than natural gas, would be expected and fossil fuels would be gradually replaced by non-carbon energy forms (renewables and nuclear energy). Such a strategic shift would also have to address energy pricing and the commercial status of alternative technologies.

An energy future that heads for controlled $\mathrm{CO}_{2}$ emissions would require a dramatic change in attitudes to energy use, particularly in the OECD, and former Soviet Union and East European (SUEE) countries. The OECD countries wuld need to achieve more rapid gains in energy efficiency than those registered in the period 1973-1988, and the SUEE countries would need to reverse their long-term historical growth in energy demand. The more advanced developing countries, and the more prosperous parts of other developing countries, would also need to achieve higher efficiency in energy use if this economic growth is to be maintained. The availability of large resources of coal in some developing countries, including China and India, is likely to lead to an increase in its use and hence to an increase in carbon emissions (at least in the medium term).

Despite measures within the energy system to mitigate climate change, further atmospheric $\mathrm{CO}_{2}$ accumulation will continue, even in instances of accelerated $\mathrm{CO}_{2}$ emission abatement. Actions taken will only postpone the doubling of $\mathrm{CO}_{2}$ concentrations by a couple of decades. It will be necessary to launch parallel efforts in other fields so as to prevent or reduce climate change or improve adaptation capabilities. These efforts would include reducing tropical deforestation, enhancing reforestation, and decreasing the release of other greenhouse-gases into the atmosphere.

Switching to an active policy of mitigating climate change will call for an increase in investments in new and revised energy systems equivalent to approximately 5-6\% of total world GNP: the burden could be significantly higher for developing countries. Uncertainties about climate change phenomena and their consequences require that the interactions of energy systems with ecology and climate at both global and regional levels be studied before major steps are taken. Attention should be paid to elaborating complex models, including all elements inducing climate change (natural and anthropogenic), determining expected social and economic impact (positive and negative) and assessing the efforts associated with their prevention or compensation. These studies would focus on energy supply and demand in developing countries, an area in need of closer investigation.

Electricity consumption will grow faster than total final energy demand. Global electricity demand will increase three- to six-fold and its share in final energy will rise from $12 \%$ in 1990 to about $20 \%$ by the middle of the 21 st century. Electricity generation, equal to $11 \times 10^{12} \mathrm{kWh}$ in 1990 , will rise to $13-16 \times 10^{12} \mathrm{kWh}$ in 2000 and $15-65 \times 10^{12} \mathrm{kWh}$ in 2050 , depending on the efforts at energy conservation, efficiency improvements and economic restructuring.

The difficulty in forecasting possible allocations from different energy sources for electricity generation up to the year 2050 is that the richer industrialized 
countries may well outbid almost all of the developing countries for convenient or preferred fuels. Given the large gas resources in the former Soviet Union and the ability of the OECD countries to outbid others for gas imports, the group of industrialized countries would probably make disproportionate use of natural gas. If the same group were also to use sufficient amounts of coal, hydro and new renewable sources of energy, there would be no need for nuclear power, even if targeted growth reached the higher demand level. However, at least in the targeted growth future, such an allocation would not leave an adequate supply of fossil fuels for the developing countries.

Policy decisions taken during the next decade on the development of energy technologies will determine which options can make significant contributions towards electricity supply over the next fifty years. It is not possible to foresee the full range of energy and electricity related future needs, nor the full range of options for meeting them. Solutions to those needs may be deterred or aided by changed perceptions, new technologies or concerns about a changing climate. It would seem prudent to seek flexibility by retaining the widest possible variety of options in order to be able to match future energy needs and changing perceptions with acceptable supplies. A decision to close off any option means that its potential contribution must be met by the options remaining.

\section{Technology options, technology transfer, and financing}

\subsection{Technology options}

In order to be accepted by industry in developing countries, advanced technology systems must meet several criteria: environmental superiority, low capital and operating costs, high efficiency and low technical risk.

As stated previously, the demand for energy will continue to increase apace with economic growth in the medium term and population growth in the longer term. It is also clear that energy resources are available in sufficient quantities in the medium term to support national development and individual well-being. In order to satisfy those national and regional energy needs that require electricity, a mix of energy-producing technologies are available that utilize all types of fuels: fossil fuels, nuclear, hydro and renewables.

In addition, public sensitivity to environmental changes will continue to increase and will call for further research efforts related to the deployment of environmentally acceptable technologies. Technologies that are expected to enter the commercialization stage within the coming decades are already at the pilot or demonstration stage or, at least, being tested at the laboratory level. It is conceivable that technologies available for commercial deployment in the second half of the next century might include, the so-called $\mathrm{CO}_{2}$ free fossil fueled power plant, nuclear fusion- or hydrogen- based energy systems, provided that no economic or social obstacles constrain the deployment. 
Fossil-fuelled power plants will continue to have a future; however, the emphasis will be on clean coal technologies and natural gas systems. Changes in power production technology are being increasingly governed by the need to reduce the costs of complying with environmental protection requirements. The serious drawback of most fossil fuels is that they produce substantial amounts of air pollutants, such as nitrogen oxides, sulphur dioxides and carbon dioxide that are believed to contribute to acid rain and climate change. By retrofitting existing power plants, where economically possible, and using advanced technologies, $\mathrm{NO}_{x}$ and $\mathrm{SO}_{2}$ can and have been reduced significantly. However, apart from switching fuels and using higher efficiency equipment, reducing carbon dioxide emissions poses significant problems. Of course, with improved fuel input, i.e. fuel with lower sulphur content, efficiencies would improve by some percentage points as less stringent abatement technologies would be required.

Photovoltaics, solar thermal and wind power systems for energy production have improved greatly over the past few decades, but considerable development efforts are still needed to make them ready for major commercial applications. Hydro and geothermal energy are already cost-effective in many situations, depending on the availability of resources. The global market potential of hydro energy for power generation in the coming decades will remain generally high both for large- and small-scale applications, whereas the potential for renewables will be less. However, renewables such as solar and wind technologies do offer large local potentials and are suitable for use as stand-alone technologies in remote areas.

As part of a balanced energy mix, nuclear power can potentially play a very substantial role in responding to global demand. Thus, there is a wide variety of technology options available (See Table 3). The shares assumed by the various options, however, will ultimately depend on future energy requirements, operational costs, technological changes and social preferences.

During the current decade and beyond, technological advancement in the oil industry in both the upstream and downstream sectors will concentrate on lowering the operating cost through the application of a new generation of computers and associated software. This would allow operators to evaluate business opportunities more rapidly and thoroughly. It will also focus on developing environmentally compatible technology to reduce pollution and other oil related detractors.

Mass transportation offers another technological option. Mass transit systems have the potential for saving millions of tonnes of oil equivalent of energy worldwide. The effective establishment and use of buses, trains, and other modes of moving large numbers of people provides flexibility in energy sourcing and reduces pollution. Furthermore, given the high cost of introducing and maintaining mass transportatin systems, the potential for this technology to play a major 
TABLE 3 Representative technologies for energy supply

Non-renewable energy technologies

Nuclear

- Conventional cooled reactor

- Advanced cooled reactor

- Fast breeder

- Gas-cooled

Fossil fuel technologies

- Diesel engines

- oil/gas fired - coal fired

- Gas turbines

- simple cycle

- combined cycle

- coal fired

- Co-generation

- Steam boilers

- stoker and pulverized coal

- oil and gas

- Advanced steam boilers

- Fluidized bed combustion

- atmospheric

- pressurized

- Coal gasification combined cycle

- Fuel cells

- Natural gas

- Integrated gasification

- Oil/gas production and utilization technologies

- Wider application of 3-D seismic surveying

- Wider use of horizontal drilling to recover additional hydrocarbons.

- Application of enhanced oil recovery techniques.

- Improved refined product quality (e.g. lead-free gasoline)

- Improvement in offshore technology

- Application of computeraided drilling.
- Improvements in refinery waste disposal

- Reduction or elimination of gas flaring

$\underline{\text { Renewable energy technologies }}$

- Hydropower

- large

- small head

- Geothermal

- conventional

- binary

- geo-pressurized

- hot dry rock

- magma

- Wind

- onshore

- offshore

- upcurrent

- Solar

- thermal

- photovoltaic

- Biomass

- harvest waste

- energy crops

- Municipal (urban) waste

- landfill gas

- direct combustion

Energy storage

- Pumped hydro

- Hydrogen fuels

- High-efficiency batteries

- Heat storage 
role among energy options is limited. Only when introduced at an early stage in a country's development cycle as an option to individual modes of travel, can mass transit systems be successful.

\subsection{Technology transfer}

For a number of years, developed countries have been carrying out research and development into the rational use of energy and securing the technological development and commercialization of the results. Technology transfer, as well as joint research activities, between both developed and developing countries are therefore of great interest. In particular, technology transfer and utilization of new and renewable sources of energy have received particular attention at national, regional and international levels.

The objectives of developing and transferring energy technologies are threefold: (i) to increase the developing countries' awareness of the implications of emerging technological changes; (ii) to facilitate developing countries access to technology sources and assist in strengthening their domestic capacities; and (iii) to promote broader participation by developing countries in international technological development. Technology transfer activities in the area of energy must in particular contribute to promoting environmentally sound industrial development.

International organizations, development agencies and national institutions are paying due attention to the transfer of different energy-related technologies in an integrated and diversified manner, taking into consideration the specific characteristics and requirements of a given country or region. In this context projects are implemented in various developing countries in a manner that permits Governments to decide on low-cost energy production alternatives using renewable resources. Typical technology transfer programmes and projects carried out by international development organizations are cited below.

UNIDO, for example, has implemented a large number of technical assistance projects on solar energy, mainly related to solar/thermal applications. In Jordan, a major project was directed towards the establishment of solar energy testing facilities and the local manufacture of solar energy collectors. UNIDO has also set up the Consultative Group on Solar Energy Research and Application (COSERA) which undertakes studies of the current and future market for photovoltaics and the largescale manufacture of solar photovoltaics to reduce unit costs.

Another example is a project in Egypt which aims at establishing manufacturing and testing facilities for the local production of wind turbines with a generation capacity of $90 \mathrm{~kW}$. Project activities included transferring technology, adapting equipment to local conditions, providing expertise and training and supplying related equipment. A network of small hydro power pilot plants in the Asia/Pacific region has been running for the past eight years with more than 20 member countries. The network's activities cover information exchange, co-operative research and development, training and the provision of consultancy services. 
Biomass programmes have been designed in response to the need to alleviate acute fuel shortages, to reduce tropical deforestation and to meet energy needs of the rural population in remote areas.

International agencies have also been transferring the most recent technological developments in gasification, fluidized bed combustion, fuel cells and direct liquefaction, which promise ways of minimizing the environmental impact of lower quality fuels. Assistance in monitoring pollution arising from coal combustion and recommending options is assuming an increasingly important role.

Programmes on the rational use of energy resources have been initiated in the steel and textile industry in selected Asian countries, thus increasing the awareness and knowledge of new energy-saving technologies on the part of Government officials, industry representatives, plant managers and engineers. Manuals on energy management and energy conservation/saving technologies are adapted to selected developing country conditions on the basis of plant observations and subsequently disseminated at seminars. Technology transfer activities related to energy conservation demonstrate the importance of increasing energy efficiency in developing countries since energy conservation reduces the pressure on finite energy resources and curtails the energy imports. Energy conservation provides a better pay-back than equal investments in energy supply, it delays and lessens the impact of increased energy costs, and reduces the environmental impact of energy production and use.

When considering future technology transfer to developing countries, it can be appreciated that the application of conventional technologies are key to increasing the potential for technological improvement in the environmental context. Also necessary are advanced technologies that can increase equipment/ system efficiency and ensure the developing countries sustainable long-term energy growth with decreased fuel use. Current electricity-generating technologies in the developed countries are capable of operating at $40 \%$ efficiency and above. Transfer of this technology to developing countries must be accelerated, yet sufficient training must also be provided so as to ensure acceptance, use and maintenance of these systems over the long term. These efforts must be supplemented by the extensive dissemination through computerized networks of information on energy conservation and cleaner energy production.

Technology transfer in the future should consider:

- An enhancement of basic technological capabilities;

- Greater awareness and use of advanced and efficient energy technologies;

- More effective application of conventional energy technologies;

- Easier access to industrial and technological information for industry; and

- Greater control of and benefit from technology transfer. 
If they are to meet the wide range of environmental concerns, new technologies will often, but not necessarily, be more expensive than traditional technologies. A significant component of generation costs is related to fuel costs, future estimates of which are subject to large margins of uncertainty.

Advanced technologies are more efficient, but they also entail higher capital costs (at least initially). The higher capital cost will be offset, however, by lower fuel cost due to better efficiency resulting in a lower lifetime cost. Gas turbines and combined cycles have a very low capital cost but high potential fuel cost. For nuclear plants in comparison to fossil fuelled plants, efficiency of fuel use is a less important technical objective, while predictable construction costs and high reliability are more essential.

Owing to the regional and time dependant nature of renewable energy resources, these technologies can serve only a rather specific part of the global load. This makes comparison difficult with technologies that serve continuously. In many instances, the advantages of renewables as being least dependent on fuel stock and least polluting are offset by the high initial costs. Major technical hurdles must still be overcome before costs are brought down to competitive levels.

Figure 1 presents the comparative costs of a representative set of technologies that could be deployed in the upcoming decades. The costs represent system life costs on a mill $/ \mathrm{kW}(\mathrm{e})$.h basis solely for comparison purposes.

[Ref. 5]

Environmental concerns will force decision makers to expand the economic evaluations of power plants and power systems, by including costs incurred at the front and back ends of the fuel cycle. The health and environmental impact of energy production and other impacts along the fuel chain have to be economically assessed before the external costs can be incorporated fully into the economics of power generation. Regardless of the technology chosen, there will always be an environmental impact.

If the world can be said to run on energy, the energy industry runs on finance. Supplying the industry's huge appetite for funds - on the scale and in the form required -has always posed a major challenge to the international banking community. But in some respects that challenge is greater today than ever before, not only because of the industry's escalating requirements but also because of the way the attitudes of banks have changed in the recent past.

A number of multilateral, bilateral, national and local barriers to funding energy projects in developing countries contribute to a distortion of the market for energy technologies. As a result, even in those applications where the free market would dictate the selection of a certain technology as a least cost alternative, less cost-effective technologies continue to be deployed. 


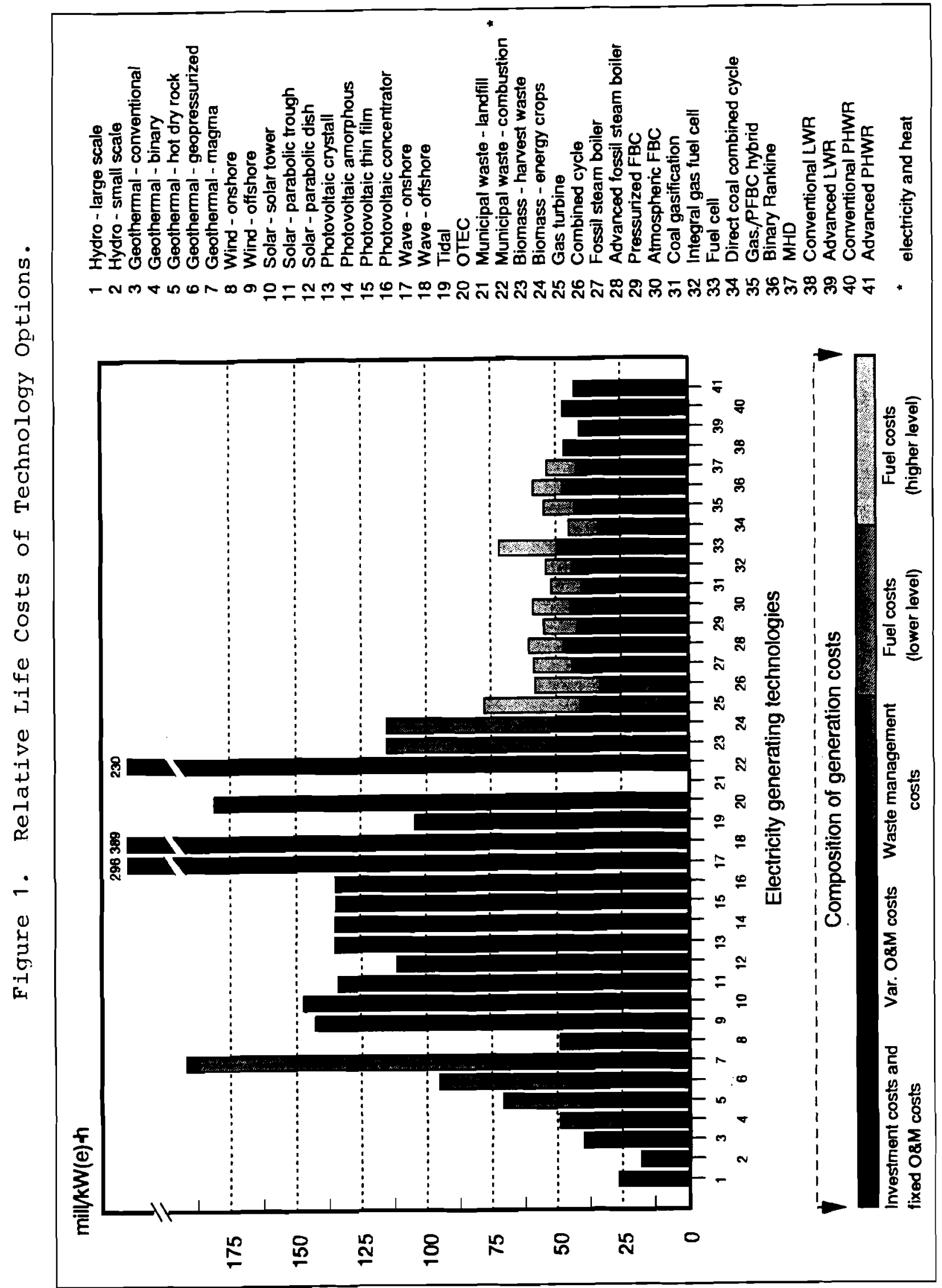


One of the most profound distortions is the bias displayed by multilateral lending institutions in favor of developing large-scale power projects in urban areas as against smaller scale projects in rural areas. Major funding agencies, the single most important source of external capital for energy activities in the developing world, tend to focus their support on major capital projects where millions of dollars are spent on individual projects. The most important multilateral lending agencies have virtually no record of financing small-scale, rural power projects - not even on a wide-scale basis to achieve economies of scale.

In addition, in those instances where large multilateral donor agencies have financed energy systems in the past, projects were often implemented on a grant basis with no financial provisions for system maintenance and repair. The lack of cost recovery to ensure system maintenance and repair has often resulted in eventual system failures for want of maintenance and repair. The issue here is the proper design of the finance component in projects. The solution is to build cost-recovery components into projects, even those funded on a grant basis, so as to secure funds for maintenance and component replacement throughout the life of the system.

At government levels, the successful dissemination and commercialization of new energy systems are hampered by several shortcomings. In addition to the failure to ensure recovery of maintenance and repair costs, fossil fuel subsidies distort the economics of a project and lead to scarce imported resources being used rather than readily available indigenous fuels; they also result in less environmentally benign systems being selected. Lack of life-cycle costing among national/regional/local government agencies is a major obstacle to the successful implementation of optimal energy solutions. Life-cycle costing, combined with undistorted conventional fuel prices, is essential to putting energy systems on an equal basis. National government energy agencies must assess all energy options and apply consistent life-cycle costing to provide a common analysis for all technologies. Efforts to convince governments to reduce their fuel subsidies should continue.

For both the banking community and the energy industry, the 1980s were a period of major change. World oil consumption dropped markedly, a supply glut developed and the influence of OPEC declined. Supplies from non-OPEC countries increased sharply. The complexity of corporate and trading relationships increased considerably, with a great variety of de-integrated sources of supply impacting on the oil markets. Market instability became a pronounced feature and still looms large today. Most recently, of course, the Gulf War added to the volatility of oil prices and uncertainties on the broad economic front. Inevitably, these features condition the attitude of the international financial community towards the energy industry as a whole.

Furthermore, the oil industry itself has changed. In the early 1980's a number of state corporations emerged in the developing countries. Elsewhere the range of players in the industry expanded significantly. However, in adapting to surplus capacity over the past few years, the industry has been undergoing a major restructuring by way of mergers, acquisitions, asset spin-offs and cost reduction programmes. This process continues today, and is leading to the emergence of a smaller, but stronger, nucleus of companies, better equipped to withstand the tough 
competitive conditions. For many, time has demonstrated once again the value of a strong, diversified, well integrated business base.

One important external constraint is the international convergence of capital adequacy standards. This has become an increasingly prominent feature on the financial scene. It impacts on all international banks involved in lending to industry, including the energy sector. It has a crucial effect on both the availability and the pricing of funds and is the underlying cause of some of the fundamental changes now taking place in the banking world. The principal aim of this concept has been to strengthen the stability of the international banking system, setting a minimum ratio of capital to assets on a bank's balance sheet. Since banks' assets vary with regard to risk, assets are risk-weighted with all lending to energy companies weighted at 100 per cent unless the exposure is guaranteed by an OECD government or bank. This has forced banks in many countries to withdraw from participation in financing energy projects.

Two major factors influence this position: One is the rapidly evolving scene within the energy business in response to the harsher competitive conditions and greater uncertainties about the future. The other is that banking itself has been undergoing significant change as a result of severe pressures and constraints, both internal and external.

\subsection{Institutional aspects of world energy development}

Industrial processes consume two fifths of the developed world's energy, but also provide the largest potential for progress in energy efficiency. The efficiency, scope and technological level of industrial development with its economic, technical, and environmental consequences and social implications depend to a large extent on the effective introduction and application of related energy technologies.

In this process many different parties, such as industrial enterprises, local energy utilities, government organizations and ministries are involved. They are far more numerous and disaggregated than those involved in energy production. Therefore, the environment in which industrial energy efficiency activities take place is very complex: it is linked to wider economic factors as well as institutional aspects. National and international energy policies have increasingly recognized the need for a more rational use of energy since energy economy and efficiency are essential to further industrial development especially where the environment is concerned. Government entities must, therefore, consider new energy policy priorities. These would include the rational use of energy, primarily through cost-effective energy pricing, trade diversification as a means of securing energy supplies and profitability as most important for reducing energy waste or developing energy resources. They would also include securing future energy production capacities, integration into wider international energy markets and protecting the environment for present and future generations.

The development of new technology is only part of the answer to the challenge of achieving an efficient energy supply system. A whole range of technological developments already exist, both on the supply and the demand side, 
but progress towards the practical application of this existing technology is painfully slow. Steps must be taken to close this gap so that available methods of stepping up energy efficiency are fully exploited and proactive. Much greater attention needs to be paid to the institutional, political, legal and organizational aspects of new energy policies. Governments must ask what the barriers are that obstruct a rational, ecologically and socially acceptable use of energy at each of the various levels concerned (domestic, transport, energy policy and procedures, industrial, local, regional), right up to the level of national policy and international co-operation. Most importantly, they must identify what means and what strategies can be employed in order to overcome those barriers and open the way to more efficient use of energy.

Having executed various industrial and energy programmes in developing countries, the international organizations have recognized that a firm multi-level institutional base is needed to implement promotional campaigns and different advisory services. Such institutional aspects include:

Conducting energy surveys, analyses and assessments of energy potentials;

Rationalizing taxation systems and eliminating subsidies where possible, while promoting installation of energy-efficient services or equipment through soft loans, preferential tax treatment, exemption from import duty, etc.;

- Implementing adequate regulations and laws, and establishing standards to promote energy conservation and improve energy pricing by "internalizing externalities";

- $\quad$ Establishing new institutional arrangements for designing appropriate energy programmes to ensure co-ordination, organizing campaigns for energy awareness and promoting regional and interregional co-operation to encourage developing countries to exchange experiences;

- $\quad$ Assembling a data and information base on appropriate energy production and conservation technologies, conducting systematic reviews of preferred energy technologies based on indigenous resources and providing technical assistance where practical; and

- $\quad$ Promoting education and training for new energy options.

\section{Conclusion}

It is apparent that while minimizing environmental impact, strategies aimed at sustainable energy growth will require national and regional measures within the broader context of international co-operation. The trade-offs between environmental impact and energy development have to be explored and incorporated into any energy policy formulation. The interdependence of economies at different levels requires a concept of equity and burden sharing that will still be flexible enough to respond to specific needs of individual countries and different regions. 
Energy conservation will play a central role in future energy strategies, but it will not eliminate the need for new supply options to meet growing demand. The challenge of the next decades will also place greater emphasis on energy sources and power generation technologies that have the potential to minimize damage to health and the environment, while at the same time being economically viable and deployable on a broad scale to meet global energy demands. Energy availability, security of supply, and the pricing structure of both primary and final energy sources are important issues on the decision-makers' agendas.

Successful integration of energy growth with environmental awareness in the 21st century will hinge on international co-operation. It will also require full recognition of the inter-dependence of global economies, optimization of energy supplies with due regard for the environment, and consumption to the ultimate advantage of the world economy. It will also call for acceptance of a long-term view towards growth and the environment, and sustainable energy development for all countries.

Although energy prices may not increase in the near future, there is still an important need among the developing countries for facilitative assistance in adapting technologies to their indigenous energy resources. In addition, some developing countries still have opportunities to exploit their own new and renewable sources of energy such as biomass, thermal, solar wind and small hydropower energy, where the technology gap has yet to be bridged. Other developing countries have underexploited deposits of low-grade coals for which technical assistance will be needed, if the environmental consequences of using these fuels are to be minimized. Thus, the developing countries require assistance in identifying and developing energy options which rely as much as possible on indigenous resources.

Selecting from available options an optimum mix of energy resources for the various industrial sectors is a critical step in industrial development. All the more so as it governs the location of new industries and constitutes a vital input to energy sector planning.

An integrated energy policy also needs to treat the provision (supply) and use (demand) of energy as two equally important parts of an overall energy service system and it should work towards improving both parts. Any energy policy of the future must be so designed that the supply and use of energy are ecologically acceptable, socially just and be as sparing as possible in its use of energy resources.

The Vienna based organizations (IAEA, IIASA, OPEC, and UNIDO) are in a unique position to provide guidance, advice and suggestions to interested government organizations and industry on the most appropriate technologies from an energy, environmental and industrial point of view. The "Vienna Four" Organizations offer assistance to developing countries in the formulation of their national energy policies and act as a bridge to existing programmes in donor countries and potential recipient countries. 


\section{References: ${ }^{2}$}

[1] OPEC Annual Statistical Bulletin, 1990

[2] Masters et al., US Geological Survey in the 13th World Petroleum Congress

[3] BP Statistical Review of World Energy, 1991

[4] NEA (OECD)/LAEA, Uranium Resources, Production and Demand, Paris, 1989

[5] CEC/CMEA/ECE/LAEA/IBRD/IEA/IIASA/NEA/UNEP/WHO/WMO, Senior Expert Symposium on Electricity and the Environment, Helsinki, Finland, 13-17 May 1991

2 Data and results presented in this paper outside the scope of recognized IIASA research areas represent the opinions of the other organizations and are not attributable to IIASA. 